\title{
Effects of Recycled Coarse Aggregate Reinforcing Treated by Water-Glass on the Performance of Recycled Concrete
}

\author{
Li-Xiang YANG ${ }^{a^{*}}$, Yao-Li QIAN ${ }^{b}$, Qian-Qian FANG ${ }^{c}$, Yun-Ting HAN ${ }^{d}$ \\ Shanghai Research Institute of Building Sciences, Shanghai 201108, China \\ ayanglixiang2007@163.com, ${ }^{b}$ qianyaoli12004416@163.com, ' $18918191887 @ 126 . c o m$, \\ 'han.yunting@163.com \\ ${ }^{*}$ Corresponding author
}

Keywords: Water-Glass, Reinforcing Treatment, Recycled Coarse Aggregate, Recycled Concrete.

\begin{abstract}
The recycled coarse aggregates were soaked in the water-glass solution with several concentrations for different soaking time. The optimal-processing recycled coarse aggregate was used to prepare the recycled concrete whose basic mechanical property and durability were studied. Tests showed: the water-glass solution could significantly reduce the water absorption of recycled coarse aggregate; recycled coarse aggregates treated by the water glass solution of low concentration could significantly increase the compressive strength of recycled concrete. When the recycled coarse aggregates were treated by the water-glass solution with modulus of 3.2 and concentration of $5 \%$, the recycled concrete`s $28 \mathrm{~d}$ compressive strength increased by $29 \%$, and with excellent durability.
\end{abstract}

\section{Introduction}

With the rapid economy construction and social development, the rate of growth in solid wastes such as construction wastes increased significantly. The statistic showed that 1 billion tons construction wastes were generated in China in 2013 of which only 5\% was utilized. They were mainly used for preparing building materials such as recycled aggregates and filling subgrade[1]. Heaps of construction wastes not only occupied lands but also had negative impacts on the environment and people`s daily life.

The recycled coarse aggregate was mixed of concretes, mortar, etc in a certain proportion which was processed by crushing, screening, etc. The surface was coated with the large amount of cement mortar. And they have plenty of sharp edges, rough surfaces and micro cracks, which were made by the mechanical forces such as crushing. Therefore, compared to natural aggregate, the recycled coarse aggregate performed higher porosity, higher water absorption and lower strength [2]. The fluidity and performance of the recycle concrete were much worse than the ordinary concrete which limited the application and progress of recycled concrete in the load-bearing components and structure materials.

In order to improve the porosity of the recycled coarse aggregate and reduce water absorption, in this paper, the effect of water-glass on reinforcing the recycle aggregate was studied. Comparing the effect of concentration and soaking time of the water-glass on the coarse aggregate's water absorption, the research optimized the method of significantly improving water absorption of recycled coarse aggregates. It was also investigated the effect of optimal-processing recycle coarse aggregate on the basic mechanical properties and durability of the recycled concrete, so as to expand its application and improve the performance of the recycled concrete.

\section{Material and Test Method}

\section{Materials}

Cement: Ordinary Portland Cement(P.O 42.5)of Shanghai Wan`an Cement Technology Development Co., Ltd.; Fly ash and Slag powder: Grade II Flyash and S95 Slag powder of Shanghai Bao Tian new building materials Co., Ltd.; Fine aggregate: natural river sand, fineness 
modulus is 3.1; Recycled coarse aggregate: provided by Shanghai Urban Construction Materials Co., Ltd. The grain gradation and basic performance of recycled coarse aggregate were shown in the table 1 and 2; Water-glass: modulus is 3.2, concentration is 40\%; Water reducing agent: high-performance poly carboxylic acid water reducing agent (solid content:20\%).

Tab. 1 Grain gradation of recycled coarse aggregate

\begin{tabular}{cccccccc}
\hline Sieve size of square hole sieve[mm] & 2.36 & 4.75 & 9.50 & 16.0 & 19.0 & 26.5 & 31.5 \\
\hline Cumulative sieve residue[\%] & 98 & 96 & 76 & 31 & 19 & 0 & 0 \\
\hline
\end{tabular}

Tab. 2 Basic performance of recycled coarse aggregate

\begin{tabular}{|c|c|c|c|c|c|c|c|}
\hline \multirow{2}{*}{$\begin{array}{c}\text { powder } \\
\text { content[\%] }\end{array}$} & \multirow{2}{*}{$\begin{array}{c}\text { Mud } \\
\text { Content }[\%]\end{array}$} & \multirow{2}{*}{$\begin{array}{c}\text { Water } \\
\text { absorption[\%] }\end{array}$} & \multirow{2}{*}{$\begin{array}{c}\text { Flat and Elongated Particles } \\
\text { content }[\%]\end{array}$} & \multicolumn{2}{|c|}{ robustness } & \multirow{2}{*}{$\begin{array}{c}\text { apparent } \\
\text { density } \\
{\left[\mathrm{kg} / \mathrm{m}^{3}\right]}\end{array}$} & \multirow[b]{2}{*}{ porosity [\%] } \\
\hline & & & & $\begin{array}{c}\text { Sodium sulfate } \\
\text { solution [\%] }\end{array}$ & $\begin{array}{l}\text { Crushing } \\
\text { index }[\%]\end{array}$ & & \\
\hline 1.6 & 0.9 & 6.1 & 2 & 7.9 & 12 & 2580 & 50 \\
\hline
\end{tabular}

\section{Test Method}

(1) Reinforcing treatment: Prepare the water-glass solution of different concentrations of 3\%, 5\%, $8 \%, 10 \%, 20 \%$, respectively. Soak the recycled aggregate for 10min, $1 \mathrm{~h}, 2 \mathrm{~h}, 5 \mathrm{~h}$ in $3 \%, 5 \%, 8 \%, 10 \%, 20 \%, 40 \%$ water-glass solutions, then take out and dry naturally.

(2) Water absorption test: Test the water absorption of the untreated and treated recycled coarse aggregates based on the national standard GB/T25177-2010(Recycled coarse aggregate for concrete).

(3) Performance test: Test the working performance, mechanical properties and durability of recycled concrete based on the GB/T50080-2002(Standard test method for the performance of ordinary concrete),GB/T 50081-2002(Standard for test method of mechanical properties of ordinary concrete), GB/T 50082-2009(Standard test method for long-term performance and durability of ordinary concrete).

\section{Test and Analysis}

\section{Effects of the Water-glass on the Water Absorption of Recycled Coarse Aggregates}

It was studied effects of different concentrations of water-glass on the water absorption of the recycled coarse aggregates under different soaking time and different dry way (dry naturally, dry under $60{ }^{\circ} \mathrm{C}$, dry under $105{ }^{\circ} \mathrm{C}$ ). Results were shown in Table 3.

Tab. 3 Water absorption of treated recycled coarse aggregate

\begin{tabular}{ccccc}
\hline No. & Water-glass concentration[\%] & Soaking time[h] & Drying temperature $\left[{ }^{\circ} \mathrm{C}\right]$ & Water absorption[\%] \\
\hline S-1 & - & - & 105 & 5.8 \\
\hline S-2 & 40 & 10 in & Natural drying & 4.2 \\
\hline S-3 & 40 & 1 & Natural drying & 3.7 \\
\hline S-4 & 40 & 2 & Natural drying & 4.6 \\
\hline S-5 & 40 & 5 & Natural drying & 4.8 \\
\hline S-6. & 20 & 1 & Natural drying & 4.3 \\
\hline S-7 & 10 & 1 & Natural drying & 4.5 \\
\hline S-8 & 8 & 1 & Natural drying & 4.5 \\
\hline S-9 & 5 & 1 & Natural drying & 4.7 \\
\hline S-10 & 3 & Natural drying & 5.0 \\
\hline S-11 & 40 & 60 & 3.8 \\
\hline S-12 & 20 & 1 & 60 & 4.4 \\
\hline S-13 & 10 & 1 & 60 & 4.5 \\
\hline S-14 & 5 & 1 & 60 & 4.8 \\
\hline S-15 & 40 & 1 & 105 & 6.3 \\
\hline S-16 & 20 & 1 & 105 & 6.1 \\
\hline S-17 & 10 & 1 & 105 & 5.6 \\
\hline
\end{tabular}

It can be seen in Tab. 3: 
(1) Under the same soaking time, the water-glass solution had positive role in the water absorption of the recycled coarse aggregates at low temperatures (natural dry and $60^{\circ} \mathrm{C}$ ). The water absorption decreased with higher concentration of water-glass solution. It was resulted that the silicic acid gel precipitated from the water-glass solution clogged the pores of recycled coarse aggregate, or reacted with the hydraulic calcium to the silicate colloid that filled in the pores of recycled aggregates, which reduced the water absorption of aggregate[3]. When the temperature was at $105^{\circ} \mathrm{C}$, the water absorption of recycled aggregates increased with higher concentration. It was resulted that some crystal water of aqueous sodium silicate got lost at high temperature, which increased the water absorption. Thus, the approach was to dry naturally in the reinforcing treatment of recycled aggregates, which was adopted in the concrete preparation experiment.

(2) At the same concentration, the water absorption of recycled aggregates decreased firstly and then increased when the soaking time prolonged. When the recycled aggregate was treated at $40 \%$ glass-water solution for $1 \mathrm{~h}$, the water absorption was decreased most significantly by $36 \%$, compared to the untreated aggregate. Thus, the soaking time was set to 1 hour in the following concrete experiment.

\section{Effect of Treated Recycled Coarse Aggregate on the Basic Performance of Recycled Concrete}

At present, the secondary concrete is commonly prepared by the recycled coarse aggregate. In the experiment, the design strength of concrete was C30, The proportion of reference concrete was as below: cement $\left(223 \mathrm{~kg} / \mathrm{m}^{3}\right)$, fly ash $\left(62 \mathrm{~kg} / \mathrm{m}^{3}\right)$, slag powder $\left(68 \mathrm{~kg} / \mathrm{m}^{3}\right)$, fine aggregate $\left(800 \mathrm{~kg} / \mathrm{m}^{3}\right)$, recycled coarse aggregate $\left(1016 \mathrm{~kg} / \mathrm{m}^{3}\right)$, water reducing agent $\left(2.82 \mathrm{~kg} / \mathrm{m}^{3}\right)$. The slump was kept for $(180 \pm 20) \mathrm{mm}$. In the experiment, the recycled coarse aggregate was soaked in the water-glass of different concentration $(3 \%, 5 \%, 8 \%, 10 \%, 20 \%, 40 \%)$ for 1 hour,and dried naturally for the preparation of recycled concrete. The results were shown in Table 4.

Tab. 4 the basic performance of the recycled concrete prepared by treated recycled coarse aggregates

\begin{tabular}{|c|c|c|c|c|c|c|}
\hline \multirow{2}{*}{ No. } & \multirow{2}{*}{$\begin{array}{l}\text { Water cement } \\
\text { ratio }\end{array}$} & \multirow{2}{*}{$\begin{array}{l}\text { Slump } \\
{[\mathrm{mm}]}\end{array}$} & \multicolumn{3}{|c|}{ Compressive strength[MPa] } & \multirow{2}{*}{$\begin{array}{l}\text { Remarks } \\
\text { (the water-glass solution of different concentration for } \\
\text { reinforcing the recycled coarse aggregates }[\%] \text { ) }\end{array}$} \\
\hline & & & $3 d$ & $7 \mathrm{~d}$ & $28 \mathrm{~d}$ & \\
\hline ZS 1-0 & 0.44 & 180 & 23.3 & 29.4 & 37.9 & - \\
\hline ZS1-1 & 0.41 & 200 & 27.9 & 33.5 & 49.5 & 3 \\
\hline ZS1-2 & 0.39 & 200 & 28.5 & 37.7 & 48.9 & 5 \\
\hline ZS 1-3 & 0.42 & 200 & 28.2 & 37.3 & 47.4 & 8 \\
\hline ZS1-4 & 0.44 & 185 & 27.9 & 36.1 & 48.7 & 10 \\
\hline ZS 1-5 & 0.44 & 200 & 26.1 & 36.1 & 44.3 & 20 \\
\hline ZS 1-6 & 0.65 & 140 & 15.8 & 20.3 & 27.7 & 40 \\
\hline
\end{tabular}

In the process of mixing concrete, the concrete mixed with the coarse aggregates that were treated by high concentration of water glass (40\%) (No.ZS1-6) became thickening. There was a substantial increase in the water consumption of concrete but poor fluidity as before, as shown in Figure 1. It was observed that the silicic acid from the water-glass hydrolysis reacted with the calcium hydroxide from the cement hydration to the hydraulic calcium silicate, which destroyed the hydrolytic equilibrium of tri-calcium silicate and di-calcium silicate. The secondary hydration was promoted causing the hydration and setting of the cement slurry accelerating. The reaction equations were as followed:

$$
\begin{gathered}
2\left(3 \mathrm{CaO} \cdot \mathrm{SiO}_{2}\right)+6 \mathrm{H} 2 \mathrm{O} \rightleftharpoons 3 \mathrm{Ca}(\mathrm{OH})_{2}+3 \mathrm{CaO} \cdot \mathrm{SiO}_{2} \cdot 3 \mathrm{H}_{2} \mathrm{O} \\
+ \\
\mathrm{Na} 2 \mathrm{O} \cdot \mathrm{SiO} 2+2 \mathrm{H} 2 \mathrm{O} \rightleftharpoons \mathrm{SiO} 2 \cdot \mathrm{H} 2 \mathrm{O}+2 \mathrm{OH}-+2 \mathrm{Na}+ \\
3 \mathrm{CaO} \cdot \mathrm{SiO}_{2} \cdot \mathrm{H}_{2} \mathrm{O}+\mathrm{H}_{2} \mathrm{O}
\end{gathered}
$$


It can be seen that the reaction became faster as the concentration of water-glass [4] increasing. The accelerating setting and hardening of the cement slurry affected the fluidity of the concrete. Thus, the concentration of water glass should not be too high in case it decreased the workability of the concrete.

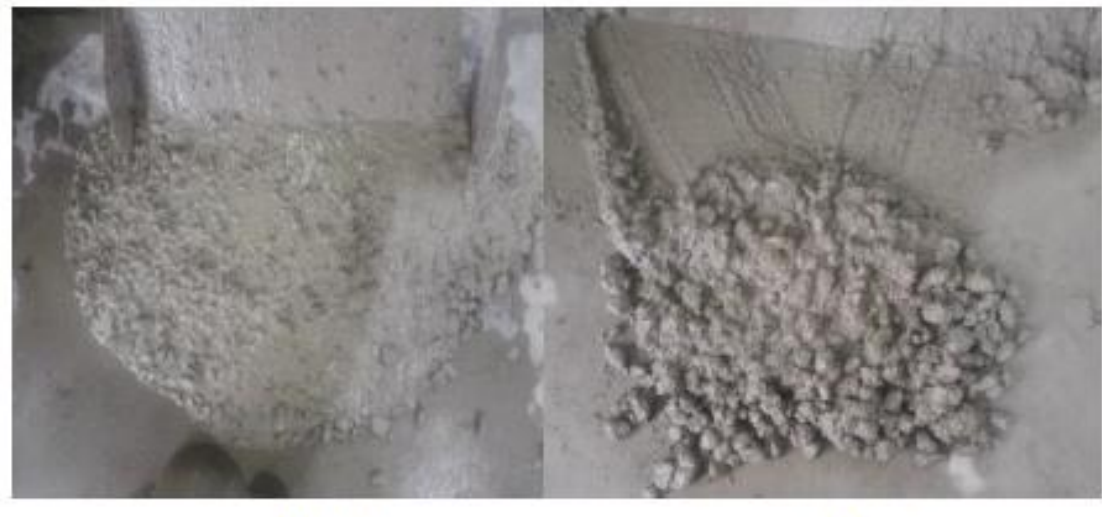

ZS1-0

ZS1-6

Fig. 1 Mixture of the recycled concrete

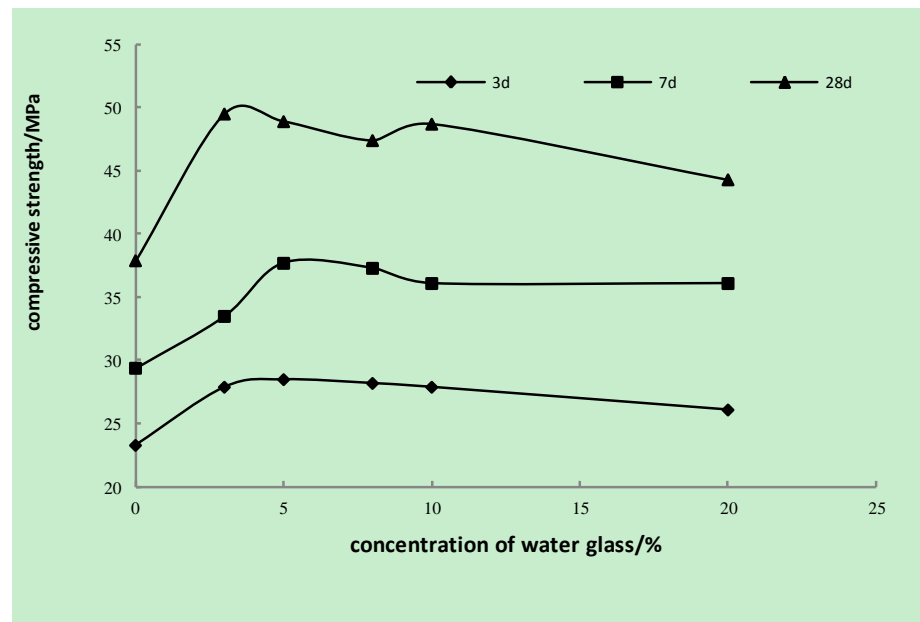

Fig.2 The mechanical properties of recycled aggregate concrete

The results were shown in Table 4:

(1)The water consumption of concrete decreased firstly and then increased with increasing concentration of water-glass solution. When the concentration was $5 \%$, the water consumption of concrete was minimum. The higher concentration was, the more the silicic acid gel precipitated from the hardened water-glass, which had a good role in the bonding and filling of aggregate pores and micro cracks. However, as the concentration further increasing, water-glass made concrete thickening which led to the increase of the water consumption.

(2)The concentration of water-glass enhanced the compressive strength of recycled concrete to different degrees. When the concentration of water-glass solution was $5 \%$, the $3 \mathrm{~d}, 7 \mathrm{~d}$, and $28 \mathrm{~d}$ compressive strength of recycled concrete increased by $22 \%, 28 \%$ and $29 \%$, compared to the reference concrete. When the concentration of water-glass was $8 \%$, The $3 \mathrm{~d}, 7 \mathrm{~d}$ and $28 \mathrm{~d}$ compressive strength of concrete increased by $21 \%, 27 \%$ and $25 \%$, respectively.

(3)With the concentration of the water-glass increasing, the compressive strength of recycled concrete of different ages showed an substantial increase firstly and then a downward trend (Fig. 2). As the concentration increasing, the aggregate precipitated more and more silicic acid gel on the surface and pores, which reacted with cement hydrates resulting in the improvement of compressive strength of recycled concrete. With further increase in the concentration, the reaction of water-glass and cement slurry speed up, which produced precipitation of hydration calcium silicate gel coated 
with various crystals mixed with unhydrated cement particles and water-glass. The arrangement of particles tended to be disorderly and pores between particles got bigger ${ }^{[4]}$, which resulted in the decrease of the compressive strength of recycled concrete.

\section{Effect of Treated Recycled Coarse Aggregate on the Durability of Recycled Concrete}

Mixed recycled concrete with recycled coarse aggregate treated by $5 \%$ water-glass solution. The performances of recycled concrete, such as mechanical property, frost resistance, chloride penetration resistance, contract performance, carbonization, etc. were tested. The results were shown in Table 5.

Tab. 5 The long-term mechanical properties and durability of the recycled concrete

\begin{tabular}{|c|c|c|c|c|c|c|c|c|c|c|c|}
\hline \multirow{3}{*}{ No. } & \multirow{3}{*}{$\begin{array}{l}\text { Water } \\
\text { cement } \\
\text { ratio }\end{array}$} & \multirow{3}{*}{ Slump $[\mathrm{mm}]$} & \multirow{2}{*}{\multicolumn{3}{|c|}{$\begin{array}{l}\text { Compressive } \\
\text { strength[MPa] }\end{array}$}} & \multirow{2}{*}{\multicolumn{2}{|c|}{$\begin{array}{c}\text { Frost-resistance } \\
\text { (freez thaw cycling for } 100 \\
\text { times) }\end{array}$}} & \multirow{3}{*}{$\begin{array}{l}\text { The diffusion } \\
\text { coefficient of } \\
\text { chloride } \\
\text { ion }\left[10^{-12} \mathrm{~m}^{2} / \mathrm{s}\right]\end{array}$} & \multicolumn{2}{|c|}{ contraction } & \multirow[b]{3}{*}{ remarks } \\
\hline & & & & & & & & & & & \\
\hline & & & $28 \mathrm{~d}$ & $56 \mathrm{~d}$ & $90 \mathrm{~d}$ & $\begin{array}{l}\text { Rate of } \\
\text { weight } \\
\text { loss[\%] }\end{array}$ & $\begin{array}{c}\text { Relative } \\
\text { dynamic } \\
\text { modulus[\%] }\end{array}$ & & $28 \mathrm{~d}$ & $56 \mathrm{~d}$ & \\
\hline $\mathrm{NJ}-0$ & 0.44 & 180 & 37.9 & 41.7 & 48.8 & 0 & 96 & 10.5 & 347 & 468 & $\begin{array}{c}\text { Treated } \\
\text { aggregates }\end{array}$ \\
\hline NJ-1 & 0.39 & 200 & 48.9 & 52.8 & 59.5 & 0 & 96 & 6.9 & 254 & 383 & $\begin{array}{l}\text { Untreated } \\
\text { aggregates }\end{array}$ \\
\hline
\end{tabular}

It can be shown in Table 5:

(1) The $3 \mathrm{~d}, 7 \mathrm{~d}$, and $28 \mathrm{~d}$ compressive strength of the recycled concrete mixed with treated recycled coarse aggregates, increased by $29 \%, 27 \%$ and $22 \%$, compared to the reference concrete.

(2) The mass loss after freeze-thaw and the relative dynamic elasticity modulus of recycled concrete were the same as those of the reference concrete. It was shown that the reinforcing treatment brought no obvious effect on the frost-resistance of the recycled concrete.

(3) The chloride ion diffusion coefficient of the recycled concrete mixed with treated recycled coarse aggregates has greatly reduced. It was shown that the micro crack and the pore of the recycled coarse aggregate were packed to enhance the chloride ion penetration resistance of the recycled concrete.

(4) After the coarse aggregate was treated, the shrinkage of the recycled concrete decreased sharply. The $28 \mathrm{~d}$ and $56 \mathrm{~d}$ shrinking rate of the recycled concrete decreased by $27 \%$ and $18 \%$ respectively, compared to the reference concrete.

Above all, the recycled concrete mixed with the recycled coarse aggregate treated by low concentration water-glass solution stood out the long-term compressive strength and durability.

\section{Conclusion}

(1) The water-glass solution had great effect on the improvement of the water absorption of recycled coarse aggregates. Compared with the untreated recycle coarse aggregates, the water absorption of recycle coarse aggregates which were soaked in glass-water with $40 \%$ concentration for 1 hour and dried naturally decreased greatly by $36 \%$.It was suggested that the soaking time and dry way of reinforcing treatment were set to $1 \mathrm{~h}$ and natural dry.

(2) The concentration of the water-glass $(\leq 20 \%)$ enhanced the compressive strength of recycled concrete to different degrees. When the concentration of the water-glass solution was $5 \%$, the $3 \mathrm{~d}, 7 \mathrm{~d}$, and $28 \mathrm{~d}$ compressive strength of recycled concrete increased by $22 \%, 28 \%$ and $29 \%$, compared to the reference concrete.

(3) There was no apparent difference between the reinforced recycled concrete (mixed with the treated coarse aggregate by $5 \%$ water-glass solution) and the reference recycled concrete in frost-resistance. While the diffusion coefficient of chloride ion and the shrinking value reduced sharply, the diffusion coefficient of chloride ion reduced by $34 \%$, the $28 \mathrm{~d}$ and $56 \mathrm{~d}$ shrinking value reduced by $27 \%$ and $18 \%$ respectively. 


\section{References}

[1] National Development and Reform Commission. Annual report on Chinese comprehensive utilization of resources.2014:15.

[2] Chen Haili, Wang Caiyan. Study on the strengthening of water-glass for the recycled concrete[J], 2004(12):p.12-14.

[3] Guo Qiji. Study on the strenghening treament of recycled aggregate and the application in the asphalt stabilized macadam[D]. Xian, Changan University, 2014.

[4] Zhang minglong. Effects of the water-glass on the hardening of cement slurry[J]. Jiangxi Coal Science \& Technology, 1999(2):p.47-50. 